American Journal of Applied Sciences 9 (3): 337-342, 2012

ISSN 1546-9239

(C) 2012 Science Publications

\title{
The Effects of Batch Reactor Extraction on Antioxidant Activity from Scurulla atropurpurea
}

\author{
${ }^{1}$ Siti Irma Rahmawati and ${ }^{2}$ Nobuyuki Hayashi \\ ${ }^{1}$ The United Graduate School of Agriculture Science, \\ Agriculture Faculty, Kagoshima University, Japan \\ ${ }^{2}$ Department Applied Biochemical Food Science, \\ Faculty of Agriculture, Saga University, Saga 840-8502, Japan
}

\begin{abstract}
Problem statement: The main active compounds of benalu teh's include alkaloids and flavonoids, therefore antioxidant of it has big potential to develop. In the context of extraction, the traditional (boiling in the water until one-third remain) extraction require a long extraction time and result in low yields of extraction also antioxidant activities. Approach: Batch reactor is extraction at high temperature under applied pressure to keep the solvent under liquid phase, by this technology we hope to obtain better results. Optimum extraction conditions of benalu teh need to be discovered to obtain the antioxidant inside it. Benalu teh was extracted using traditional and batch reactor with different solvents (water, 30, 50, 70 and $99 \%$ ethanol) at different temperatures $\left(40-180^{\circ} \mathrm{C}\right)$ for different time periods (10-20 min) under additional pressure 0.2 MPa. Results: The best extraction condition by batch reactor extraction was $30 \%$ ethanol solvent at temperature $100^{\circ} \mathrm{C}$ for $10 \mathrm{~min}$. Conclusion: Batch reactor extraction gave a better result than traditional extraction on extract yield, radical scavenging activities and total phenolic compound compared with the traditional extraction.
\end{abstract}

Key words: Extraction, benalu teh, flavonoid

\section{INTRODUCTION}

Mistletoe is a semi-parasitic plant that is considers as an unwanted plant because attached to the economically important horticultural plant and reduce production. However on the other side, mistletoe has been known as one of the medicinal plants used in traditional therapy. One of the mistletoe varieties often used in Indonesia as medicine is tea mistletoe. It's locally known as Benalu Teh.

The main active compounds in benalu teh include bioactive lipid, alkaloids, flavonoids and others components (Ohashi et al., 2003). Flavonoids inside benalu teh consist of quercetin and its glycoside, both of have strong antioxidant activity (Ikawati et al., 2008).

An antioxidant is a compound that has ability to inhibit oxidation rate or to neutralize a free radicals (Roberts, 2008). Oxidative damage is caused by free radicals that may be related to aging and diseases, such as atherosclerosis, diabetes and cancer. Therefore, the antioxidant inside benalu teh has good potential as an antioxidant.

In the context of extraction, the traditional extraction method of boiling in the water until one-third of the solution remains which is not effective due to time spent and energy consumed. Different technologies can be applied to obtain extracts with a high concentration of selected active principles. Moreover, solvents of various polarities and temperatures can be utilized to adjust its selectivity (Valle et al., 2005). In this research we used batch reactor extractor to keep the solvent in liquid phase even on high temperature by adding pressure higher than vapor pressure. Through this technology we hoped to obtain better result than the traditional method.

Ethanol, a polar solvent, effectively extracts flavonoids and their glycosides from raw materials (Bazykina et al., 2002), but solubility of these compounds can be enhanced using a mixed solvent over a limit compositional range (Cacace and Mazz, 2003). Particularly, mixtures of alcohol and water have revealed to be more efficient in extracting phenolic constituent than the corresponding mono-component solvent system (Yilmaz and Toledo, 2006).

Temperature and time of extraction are important parameters to be optimized in order to minimize energy

Corresponding Author: Nobuyuki Hayashi, Department Applied Biochemical Food Science, Faculty of Agriculture, Saga University, Saga 840-8502, Japan Tel: 81-0952-288751 
cost of the process. Not only does an increase in the working temperature extraction enhance both the solubility of the solute and the diffusion coefficient, but also denaturized phenolic compounds beyond a certain value (Yilmaz and Toledo, 2006).

This research compared traditional and batch rector extraction. It also examined the extraction with different treatments of solvent, temperature and time to obtain the antioxidant within the benalu teh. The extracts antioxidant activities were then analyzed by radical scavenging activities and total phenolic content. The best extraction condition will be continuing to HPLC analysis to find out the flavonols content in the extract.

\section{MATERIALS AND METHODS}

Materials: Dried benalu teh (Scurulla atropurpurea (BL) Dans.) was obtained in September 2008 from Puncak area, Bogor, Indonesia. The specimen was identified at Herbarium Bogoriense Bogor, Indonesia. The intact plant was ground by Willey mill 1029- A type Yoshida Seisakusho Co. with screen size $1 \mathrm{~mm}$ into powder as the range size of 200-500 $\mu \mathrm{m}$. All reagents for this research were analytical grade.

Extraction: Extraction was examined by traditional method (=decoction/boiling) and batch reactor that has specified tube reactor made from 1/2 inch SUS316 stainless tube with volume $6 \mathrm{ml}$ and mantle heater made from stainless vessel (Fig. 1). Traditional extraction started with measuring $15 \mathrm{~g}$ of sample then addition of 300 $\mathrm{ml}$ of water. Next, the mixture was boiled a under bunsen burner until a volume of $100 \mathrm{~mL}$ remained (1-2 h). On the other hand $0.5 \mathrm{~g}$ of the samples were then extracted by batch reactor through treatment with different solvent that is $5 \mathrm{~mL}$ water or ethanol $(30,50$, 70 and $99 \%$ ) at temperature $100^{\circ} \mathrm{C}$ for $10 \mathrm{~min}$ and 0.2 $\mathrm{MPa}$ of additional pressure was applied by adding $\mathrm{N}_{2}$ gas to prevent phase change of the solvent at higher boiling point temperature. Next the reactor was immersed into an oil bath for heating. After predefined time heating, the reactor was immersed into a cooling bath. So the necessary time to increase and decrease the solvent temperature was about 120 and $30 \mathrm{sec}$, respectively. In addition, solvent temperature was measured by K-type thermocouple that is located inside the reactor. The temperature was measured directly, accurately and without delay. Another treatment was applied at $40-180^{\circ} \mathrm{C}$ temperatures using the best solvent treatment while other conditions were static.

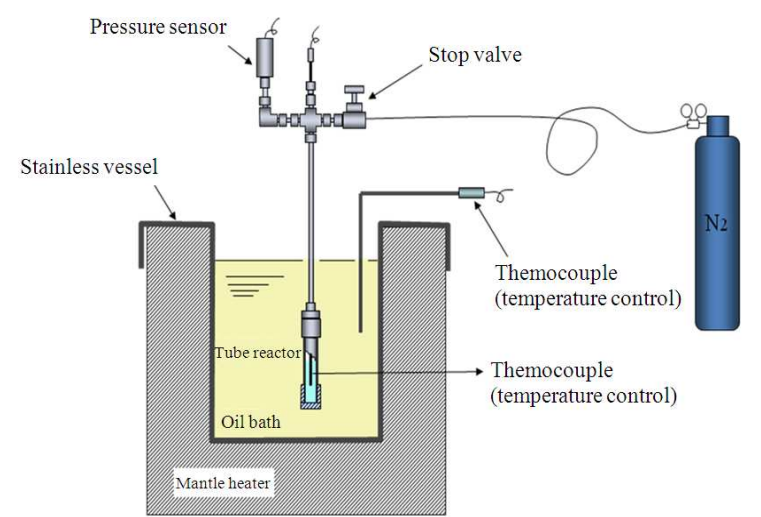

Fig. 1: Batch reactor extraction type

Last treatments of different times 10, 15 and $20 \mathrm{~min}$ were used on the best solvent and temperature condition while pressure static. After cooling down, the extracts were filtered by 2 step filtration using paper filter 90 $\mathrm{mm}$ then $0.2 \mu \mathrm{m}$ syringe filter. Next, evaporated and concentrated by centrifugal evaporation (EYELA CVE 2000 ) in vacuum condition at temperature $80^{\circ} \mathrm{C}$. Finally the extracts were lyophilized to give an amorphous powder. For chemical analysis sample, the dry extract was dissolved in water at $1 \mathrm{mg} / \mathrm{ml}(\mathrm{w} / \mathrm{v})$.

Chemical analysis: Radical scavenging activities (ABTS assay) Radical scavenging activities of extracts was measured as the ability of ABTS or 2,2'-azinobis(3-6-sulfonicacid-Ethylbenzthiazoline) diammonium salt radical cation reduction capability. ABTS was dissolved in water to a $7 \mathrm{mM}$ concentration. ABTS radical cation $\left(\mathrm{ABTS}^{+}\right)$was produced by reacting $5 \mathrm{ml}$ ABTS stock solution with $140 \mathrm{mM}$ potassium persulfate $88 \mu \mathrm{L}$ and allowing the mixture to stand in a dark at room temperature for 12-16 h. Next the $\mathrm{ABTS}^{+}$solution was diluted with ethanol $155 \mathrm{~mL}$. Each sample $\left(1 \mathrm{mg} \mathrm{m}^{-1}\right.$ $\mathrm{w} / \mathrm{v})$ and trolox as standard $(0.2 \mathrm{mM})$ was diluted in ethanol until $1.5 \mathrm{ml}$ and then mixed with $1.5 \mathrm{~mL}$ $\mathrm{ABTS}^{+}$solution. After that, it was left to stand in water bath $\left(25^{\circ} \mathrm{C}\right)$ for $10 \mathrm{~min}$, absorbance at $630 \mathrm{~nm}$ was measured by UV-VIS JASCO V-530 spectrophotometer (Re et al., 1999).

Total phenolic content: Total phenolic content was based on the method by Slinkard and Singleton (1977) with slight reduction in the volumes. First made gallic acid stock solution was used to make a standard curve. From each calibration solution (sample or blank), 20 $\mu \mathrm{L}$ were pipetted into separated cuvettes. Next 1.58 
$\mathrm{mL}$ water and $100 \mu \mathrm{L}$ of the Folin-Ciocalteu reagent (Sigma Aldrich) were added and mixed well. After between $30 \mathrm{sec}$ and $8 \mathrm{~min}, 300 \mu \mathrm{L}$ of the sodium carbonate solution was added then mixture was shaken well. The solutions were left at $40^{\circ} \mathrm{C}$ for $2 \mathrm{~h}$ and absorbance of each solution at $765 \mathrm{~nm}$ was determined against the blank.

HPLC analysis: The authentic standards Quercetin and Rutin were purchased from Sigma Aldrich Japan and Quercetin 4'-O- $\beta$-glucopyranoside (Quercetin 4'glucoside) from Polyphenols Laboratories Co, Norway. An Inteligent HPLC Pump 880-PU was used with column Ascentis Sigma Aldrich Amine ${ }_{18}$ (length $\times$ I.D, $250 \mathrm{~mm} \times 5.0 \mathrm{~mm}$ i.d) and a column heater Sugai U-620 type VP50 $\left(36^{\circ} \mathrm{C}\right)$. Mobile phases were $0.2 \%$ formic acid and methanol with flow rate $1 \mathrm{ml} / \mathrm{min}$ and concentration gradient elution $25-70 \%$ ended at 50 min and changed linearly. Flavonols were detected by Hitachi L-4000 UV detector (360 nm). First, dry extract was dissolved in solvent used in the extraction in 1 $\mathrm{mg} / \mathrm{ml}(\mathrm{w} / \mathrm{v})$ concentration. Then, the extracts were injected into HPLC through $20 \mu \mathrm{L}$ sample loop and there after filtered by $0.2 \mu \mathrm{L}$ syringe filter.

\section{RESULTS}

This experiment showed that the extract yield from different extractions and treatments is $32-136 \mathrm{mg} \mathrm{g}-1$ dry base benalu teh $(\mathrm{w} / \mathrm{w})$. The traditional extraction was resulted an extract yield of $52 \mathrm{mg}$ g-1 dry base benalu teh. On the other hand, using a mixture of ethanol and water as a solvent increased the extract yield compared to the traditional extraction of using water as solvent extraction. Moreover, batch reactor extraction increased the extract yield in a shorter time, only $10 \mathrm{~min}$, at $100^{\circ} \mathrm{C}$ and above, compared to the traditional one. All data extract yield can be seen in Fig. 2 .

We obtained the highest activities of antioxidant and total phenol content at 30\% ethanol (Fig. 3). The radical scavenging activities with treatment of different temperature were in the range 140-160 $\mu \mathrm{g}$ trolox equivalent/1 g dry base benalu teh. The highest total phenolic content was obtained by $30 \%$ ethanol solvent extraction treatment, its $15.2 \mathrm{mg}$ equivalent gallic acid/1 $\mathrm{g}$ dry benalu teh. The use of water as a solvent extraction only resulted in approximately half the value of total phenolic content that was produced by $30 \%$ ethanol solvent treatment, it was $6.7 \mathrm{mg}$ equivalent gallic acid/1 $\mathrm{g}$ dry benalu teh.
Total phenolic content from treatment of different temperature showed increasing value by increasing temperature until temperature $100^{\circ} \mathrm{C}$, but then it decreases until temperature $140^{\circ} \mathrm{C}$ and it slightly increases again at $160^{\circ} \mathrm{C}$ (Fig. 4). That is a slight difference in total phenolic content between temperature 100 and $160^{\circ} \mathrm{C}$. The value of total phenolic content on temperature $100^{\circ} \mathrm{C}$ was $17.8 \mathrm{mg}$ gallic acid equivalent/1 $\mathrm{g}$ dry benalu teh.

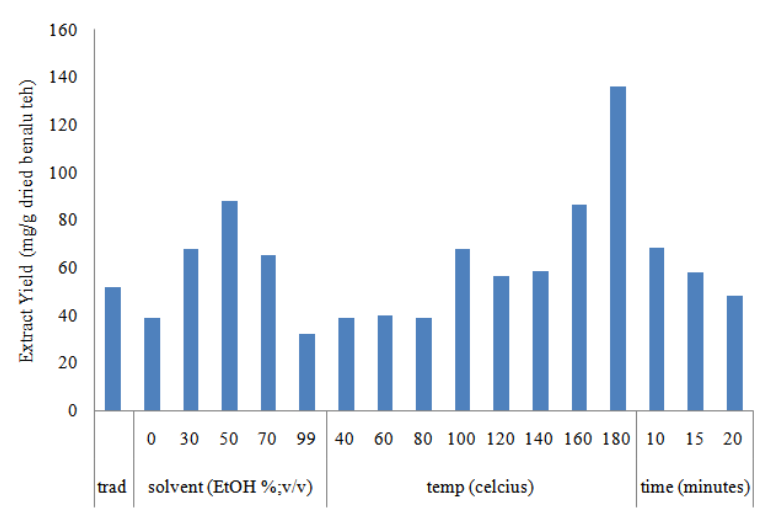

Fig. 2: Extractions yield all treatment. Trad (traditional extraction; boiling in the water until one-third remain) and batch reactor extraction with treatment solvent (solvent 0, 30, 50, 70 and 99\% $\mathrm{EtOH}$ at temperature $100^{\circ} \mathrm{C}$ for 10 min under pressure 0.2 MPa), temperature (temperature 40$180^{\circ} \mathrm{C}$ with solvent $30 \% \mathrm{EtOH}$, for 10 min under pressure $0.2 \mathrm{MPa}$ ) and time (time $10-20 \mathrm{~min}$ with solvent $30 \% \mathrm{EtOH}$ at temperature $100^{\circ} \mathrm{C}$ under pressure $0.2 \mathrm{MPa}$ )

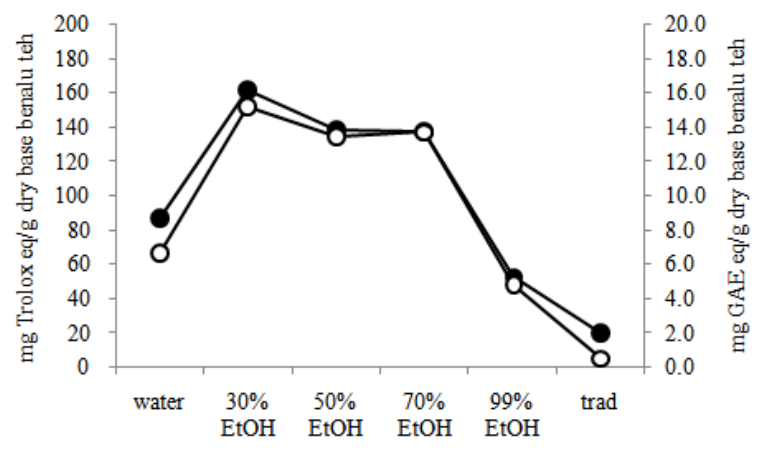

Fig. 3: ABTS (mg Trolox eq/g dry base benalu teh) and TPC (mg GAE eq/g dry base benalu teh) values from different treatment of solvents $(0$, $30,50,70,99 \% \mathrm{EtOH})$ at temperature $100^{\circ} \mathrm{C}$ for $10 \mathrm{~min}$ under pressure $0.2 \mathrm{MPa}$ and traditional extraction (trad) 
Am. J. Applied Sci., 9 (3): 337-342, 2012

Table 1: ABTS (mg Trolox eq/g dry base benalu teh) and TPC (mg GAE eq/g dry base benalu teh) values from different treatment of solvents, temperatures and times extraction condition

\begin{tabular}{|c|c|c|c|c|c|c|c|c|c|c|c|c|c|c|c|c|}
\hline \multirow[b]{3}{*}{ Assay } & \multicolumn{16}{|c|}{ Extraction treatment } \\
\hline & \multicolumn{5}{|c|}{ Solvent (ethanol v/v) } & \multicolumn{8}{|c|}{ Temperature $\left({ }^{\circ} \mathrm{C}\right)$} & \multicolumn{3}{|c|}{ Time (min) } \\
\hline & $0 \%$ & $30 \%$ & $50 \%$ & $70 \%$ & $99 \%$ & 40 & 60 & 80 & 100 & 120 & 140 & 160 & 180 & 10 & 15 & 20 \\
\hline$\overline{\mathrm{ABTS}}$ & 87.0 & 161.0 & 138.0 & 138.0 & 53.0 & 141.0 & 152.0 & 156.0 & 172.0 & 170.0 & 152.0 & 169.0 & 163.0 & 168.0 & $\begin{array}{l}168.0 \\
\end{array}$ & 145.0 \\
\hline TPC & 6.7 & 15.2 & 13.5 & 13.5 & 4.8 & 13.9 & 15.6 & 17.6 & 17.8 & 16.2 & 15.8 & 18.5 & 18.4 & 15.3 & 15.3 & 8.3 \\
\hline
\end{tabular}

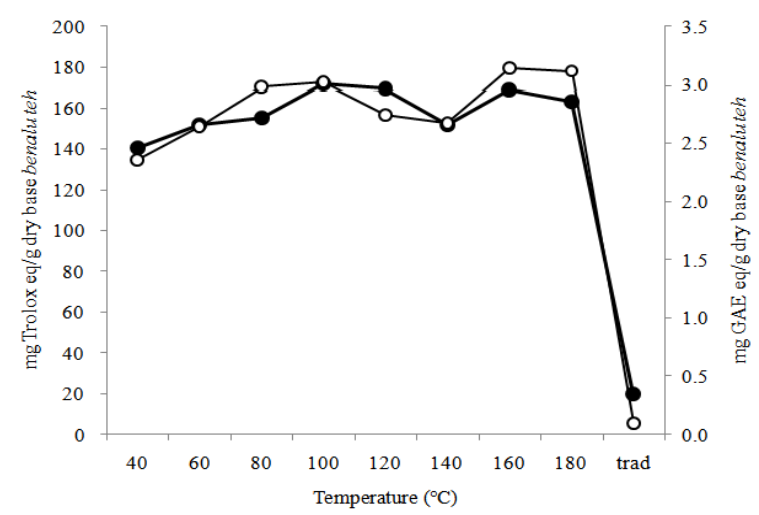

Fig. 4: ABTS (mg Trolox eq/g dry base benalu teh) and TPC (mg GAE eq/g dry base benalu teh) values from different treatment of temperature $\left(40-180^{\circ} \mathrm{C}\right)$ with solvent $30 \% \mathrm{EtOH}$, for 10 min under pressure $0.2 \mathrm{MPa}$ and traditional extraction (trad)

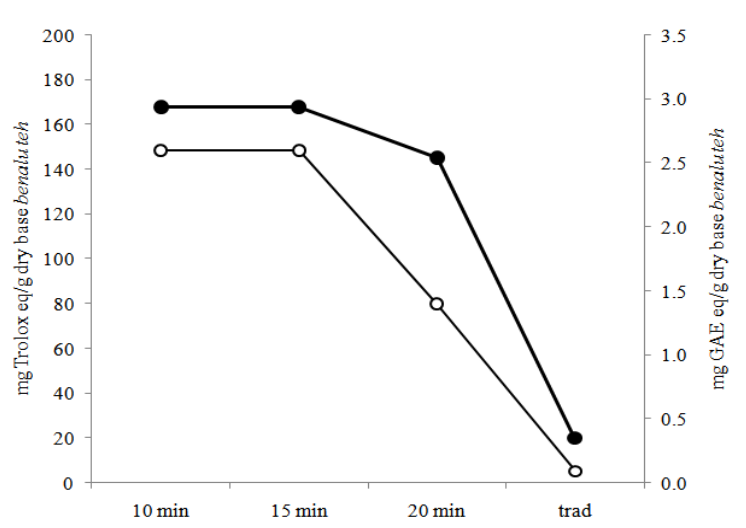

Fig. 5: ABTS (mg Trolox eq/g dry base benalu teh) and TPC (mg GAE eq/g dry base benalu teh) values from different treatment of time 10-20 minwith solvent $30 \% \mathrm{EtOH}$ at temperature $100^{\circ} \mathrm{C}$ under pressure $0.2 \mathrm{MPa}$ ) and traditional extraction (trad)

The different time treatment (Fig. 5) showed that 10 and 15 minutes have same value on radical scavenging activities that is $168 \mu \mathrm{g}$ trolox equivalent/ $1 \mathrm{~g}$ dry base benalu teh and total phenolic content it's were 15.3 $\mathrm{mg}$ gallic acid equivalent/1 g dry benalu teh.

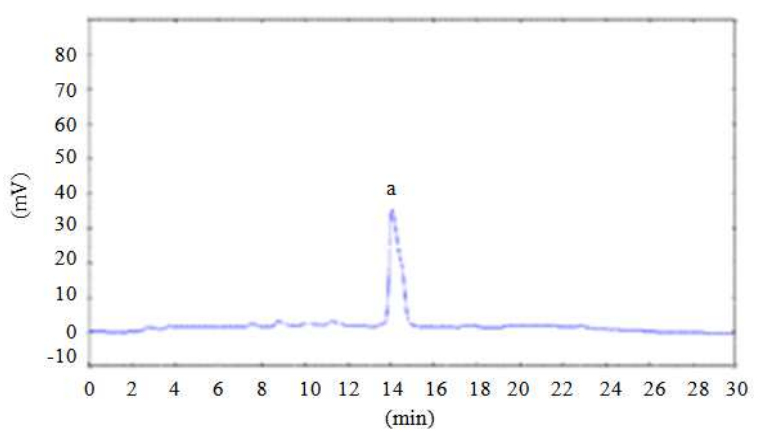

Fig. 6: Chromatogram of extract benalu teh with extraction treatment $30 \%$ ethanol solvent at temperature $100^{\circ} \mathrm{C}$ for 10 min under $0.2 \mathrm{MPa}$; peak) rutin

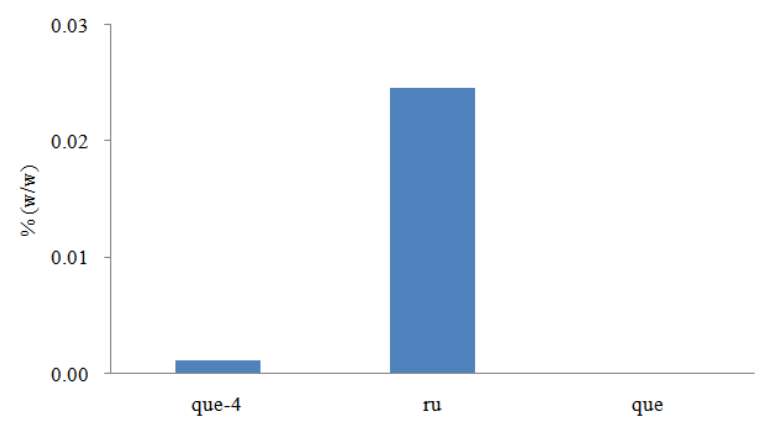

Fig. 7: Flavonoid content from benalu teh extract with extraction condition 30\% ethanol solvent at temperature $100^{\circ} \mathrm{C}$ for $10 \mathrm{~min}$ under $0.2 \mathrm{MPa}$

At 20 minutes the analysis values decreased, it become $145 \mu \mathrm{g}$ trolox equivalent/ $1 \mathrm{~g}$ dry base benalu teh for radical scavenging activities and $8.3 \mathrm{mg}$ gallic acid equivalent/1 g dry benalu teh for total phenolic content. The chemical analysis data result can be seen in the Table 1 .

The chemical analysis data showed that the optimum extraction condition was $30 \%$ ethanol solvent at temperature $100^{\circ} \mathrm{C}$ for $10 \mathrm{~min}$ under $0.2 \mathrm{MPa}$. After that the flavonoid content inside was analyzed by HPLC (Fig. 6). Rutin was the highest flavonoid compound in the extract; with $0.026 \%(\mathrm{w} / \mathrm{w})$ followed by Quercetin 4-glucoside that has $0.003 \%(\mathrm{w} / \mathrm{w})$ in the extract (Fig.7). 
Am. J. Applied Sci., 9 (3): 337-342, 2012

\section{DISCUSSION}

Benalu teh as sample was prepared in powder form to result an optimum condition of extraction. Reduction of particle size should increase the superficial area available for mass transfer then increase the extraction yield. This research used the sample that has size $1 \mathrm{~mm}$ and above. Bonilla et al. (1999) reported a higher extraction of phenolic compounds by acting a crushed than on uncrushed sample.

Conventional extraction methods such as traditional extraction have several drawbacks; e.g. they require a long extraction time and result in low yields of extraction. Another attractive alternative to obtain antioxidants is the use of batch reactor. It uses a polarity solvent extraction with high temperature (above $100^{\circ}$ C). Batch reactor system also uses the addition of pressure to maintain the solvent in liquid state.

Radical scavenging activities and total phenolic content assay showed the best value on $30 \%$ ethanol solvent treatment. Alcoholic solvent have been commonly employed to extract phenolics from natural sources. It gave high yield of total extract even though it was not highly selective for phenols. Particularly, mixtures of alcohol and water have revealed to be more efficient in extracting phenolic constituent than the corresponding mono-component solvent system (Yilmaz and Toledo, 2006).

The treatments of different temperature showed similar value on the radical scavenging activities (Fig. 4). It is assumed that the active compound inside benalu teh had already been extracted at lower temperature. So it's not necessary to use high temperature. On the other hand fast and efficient extraction is achieved by applying high pressure and elevated temperature. It was found that using higher temperatures resulted in higher recovery rates (Pineiro et al., 2004).

However different situation was happened on the total phenolic content assay. The increasing value again at $160^{\circ} \mathrm{C}$ after decreasing moment that begins at $120^{\circ} \mathrm{C}$ can caused by temperature extraction is too high. Not only flavonoid compound was extracted but also the hemicelluloses and lignin in the benalu teh were decomposed. Moreover, at temperature $100^{\circ} \mathrm{C}$ obtained the optimum extract of flavonoid compound inside the benalu teh thus at high temperature, solvent inside the batch reactor was kept in the liquid state due to the addition of pressure. Then solvent's polarity was decreased and antioxidant solubility was increased, as temperature increased (Kruse and Dinjus, 2007).

The different time treatment showed that longer extraction time decreases the chemical analysis value. It was caused by phenolic compound gradually denaturizing by association of increasing time and temperature. The shorter time of extraction can minimize the damage to phenolic compound. Chemical analysis data result can be seen in the Table 1 .

The main compound of the extract was rutin as determined by HPLC analysis. Higher water composition in the solvent can aid in the extraction of glycoside flavonoid, although due to complexity of heterosidic combinations, certain groups of flavonoids, such as flavones and flavanols, are not generally characterized as intact compound but in the form of their aglycones (Tsao and Deng, 2004).

Benalu teh has flavonoid compounds inside the leaf and their stem. As a semi parasitic plant, benalu teh still photosynthesizes. On their stem, a flavonoid compound that cause by haustorium was found. Haustorium serves several functions for the parasite: it attaches the parasite to the host, it invades host tissue through a combination of enzymatic and physical processes and it serves as the physiological conduit through which the parasite robs the host plant of water and nutritional resources (Albrecht et al., 1999). Many of active haustoriuminducing molecules are common constituents of plant cell, where they function in lignin biosynthesis, host defense and other specialized physiological processes, including phenolic compound such as flavonoid.

\section{CONCLUSION}

Benalu teh as a semi parasitic plant has the potentiality as a nutraceutical resource, because it has flavonoid compounds. Batch reactor extraction gave a better result than traditional extraction on extract yield, radical scavenging activities and total phenolic compound. Furthermore the best extraction treatment is the use of solvent $30 \%$ ethanol at temperature $100^{\circ} \mathrm{C}$ for $10 \mathrm{~min}$. The main flavonoid compound of the extract is rutin and there were so many researches about its functionalities as nutraceutical compound.

For further research, it should be explore another bioactive compound beside the flavoniod. Moreover to know the functional activities from the extract benalu teh that already extracted.

\section{REFERENCES}

Albrecht, H., J.I. Yoder and D.A. Philips, 1999. Flavonoids promote haustoria formation in the root parasite Triphysaria versicolor. Plant Physiol., 119: 585-592. DOI: 10.1104/pp.119.2.585 
Bazykina, N.I., A.N. Nikolaevskii, T.A. Filipenko and V.G. Kaloerova, 2002. Optimization of conditions for the extraction of natural antioxidants from raw plant materials. Pharm. Chem. J., 36: 46-49. DOI: 10.1023/A:1016024300843

Bonilla, F., M. Mayen, J. Merida and M. Medina, 1999. Extraction of phenolic compounds from red grape marc for use as food lipid antioxidants. Food Chem., 66: 209-215. DOI: 10.1016/S03088146(99)00046-1

Cacace, J.E. and G. Mazz, 2003. Optimization of extraction of anthocyanins from black currants with aqueous ethanol. J. Food Sci., 68: 240-248. DOI: $10.1111 / \mathrm{j} .1365-2621.2003 . t b 14146 . x$

Ikawati, M., A.E. Wibowo, N.S. Octa and R. Adelina, 2008. Extract of Mistletoe as an anticancer agent (in Indonesian). Gadjah Mada University.

Kruse, A. and E. Dinjus, 2007. Hot compressed water as reaction medium and reactant: Properties and synthesis reactions. J. Supercritical Fluids., 39: 362-380. DOI: 10.1016/j.supflu.2006.03.016

Ohashi, K., H. Winarno, M. Mukai, M. Inoue and M.S. Prana et al., 2003. Indonesian Medicinal Plants. $\mathrm{XXV}$. cancer cell invasion inhibitory effects of chemical constituents in the parasitic plant Scurrula atropurpurea (Loranthaceae). Chem. Pharm. Bull., 51: 343-345. DOI: $10.1248 / \mathrm{cpb} .51 .343$
Pineiro, Z., M. Palma and C.G. Barroso, 2004. Determination of catechins by means of extraction with pressurized liquids. J. Chromatography A., 1026: 19-23. DOI: 10.1016/j.chroma.2003.10.096

Roberts, K., 2008. Handbook of Plant Science. 1st Edn., Wiley-Interscience, Chichester, ISBN: 9780470057230, pp: 1648.

Re, R., N. Pellegrini, A. Proteggente, A. Pannala and M. Yang et al., 1999. Antioxidant activity applying an improved abts radical cation decolorization assay. Free Radical Biol. Med., 26: 1231-1237. DOI: 10.1016/S0891-5849(98)00315-3

Slinkard, K. and V.L. Singleton, 1977. Total phenol analysis: Automation and comparison with manual methods. Am. J. Enol. Vitic., 28: 49-55.

Tsao, R. and Z. Deng, 2004. Separation procedures for naturally occurring antioxidant phytochemicals. J. Chromatography $\quad$ B., $\quad 812$ : 85-99. DOI: 10.1016/j.jchromb.2004.09.028

Valle, J.M.D., T. Rogalinski, C. Zetzl and G. Brunner, 2005. Extraction of boldo (Peumus boldus M.) leaves with supercritical $\mathrm{CO}_{2}$ and hot pressurized water. Food Res. Int., 38: 203-213. DOI: 10.1016/j.foodres.2004.09.010

Yilmaz, Y. and R.T. Toledo, 2006. Oxygen radical absorbance capacities of grape/wine industry byproducts and effect of solvent type on extraction of grape seed polyphenols. J. Food Comp. Anal., 19: 41-48. DOI: 10.1016/j.jfca.2004.10.009 